\title{
Commentary: Single-stranded telomere-binding protein employs a dual rheostat for binding affinity and specificity that drives function
}

\author{
Ĺubomír Tomáška ${ }^{1 *}$, Jozef Nosek ${ }^{2}$, Regina Sepšiová ${ }^{1}$, Filip Červenák ${ }^{1}$, Katarína Juríková ${ }^{1}$, \\ Katarína Procházková ${ }^{1}$, Martina Neboháčová ${ }^{2}$, Smaranda Willcox ${ }^{3}$ and Jack D. Griffith ${ }^{3}$ \\ ${ }^{1}$ Department of Genetics, Faculty of Natural Sciences, Comenius University in Bratislava, Bratislava, Slovakia, ${ }^{2}$ Department \\ of Biochemistry, Faculty of Natural Sciences, Comenius University in Bratislava, Bratislava, Slovakia, ${ }^{3}$ Lineberger \\ Comprehensive Cancer Center, University of North Carolina, Chapel Hill, NC, United States
}

Keywords: evolution, yeast, telomere-binding protein, DNA-protein interaction, telomere

OPEN ACCESS

Edited by:

Arturo Londono-Vallejo,

UMR3244 Dynamique de l'Information

Génétique Bases Fondamentales et

Cancer, France

Reviewed by:

Carole Saintomé,

Muséum national d'Histoire Naturelle,

France

Marie-Josèphe Giraud-Panis,

IRCAN Laboratory, France

*Correspondence:

Lubomir Tomáška

lubomir.tomaska@uniba.sk

Specialty section:

This article was submitted to

Genetics of Aging,

a section of the journal

Frontiers in Genetics

Received: 18 October 2018 Accepted: 22 December 2018

Published: 15 January 2019

Citation:

Tomáška Ĺ, Nosek J, Sepšiová $R$,

Červenák F, Juríková $K$,

Procházková K, Neboháčová $M$,

Willcox S and Griffith JD (2019)

Commentary: Single-stranded telomere-binding protein employs a dual rheostat for binding affinity and

specificity that drives function.

Front. Genet. 9:742.

doi: 10.3389/fgene.2018.00742

\section{A Commentary on}

Single-stranded telomere-binding protein employs a dual rheostat for binding affinity and specificity that drives function

by Glustrom, L. W., Lyon, K. R., Paschini, M., Reyes, C. M., Parsonnet, N. V., Toro, T. B., et al. (2018) Proc. Natl. Acad. Sci. U.S.A. 115, 10315-10320. doi: 10.1073/pnas.1722147115

During evolution, protein-ligand interactions are continuously subjected to natural selection to generate their particular kinetic properties quantified in terms of binding affinities or specificities. Three decades ago (Kováč, 1987), it was argued that there is an upper limit for the specificity of interaction between binding partners (e.g., enzyme-substrate, ligand-receptor, protein-DNA sequence), since interactions that are too specific would lack flexibility, and a perfect recognition would be too rigid and possibly non-functional. This would imply that in some cases a decrease in specificity of binding might be beneficial for the host, especially when the more promiscuous binding might be helpful to keep up with an increased rate of evolutionary diversification of the ligands.

Telomeres, the nucleoprotein complexes at the ends of linear DNA chromosomes, are particularly useful for studying the evolution of DNA-protein interactions. With some exceptions, such as Drosophila (Kordyukova et al., 2018), the telomeric DNA consists of an array of short tandem repeats, where the double-stranded (ds) region is followed by a relatively short 3' singlestranded (ss) overhang. Both parts of telomeric DNA are bound by telomere-binding proteins (TBPs) constituting a platform for the formation of a protein complex called shelterin that plays essential roles in solving the end-replication and end-protection problems associated with the chromosomal termini (de Lange, 2018). Telomeric DNA repeats are very conserved, and in most eukaryotes, they are represented by the hexanucleotide $5^{\prime}$-TTAGGG-3' or its variants (Blackburn, 2010). This is also the case for most basidiomycetous and ascomycetous fungi, such as Ustilago maydis (Guzmán and Sánchez, 1994) and Neurospora crassa (Schechtman, 1990), which harbor mammalian-type telomeric repeats. However, in hemiascomycetes, the telomeric repeats underwent a runaway evolution (Gunisova et al., 2009). In these fungi, the length, sequence and base composition of the repeats differ dramatically even between closely related species (Table 1). The situation is even more pronounced in species possessing heterogeneous telomeric repeats such as Saccharomyces cerevisiae and Schizosaccharomyces pombe. This poses a great challenge to TBPs, whose binding properties must rapidly co-evolve with their DNA targets (Steinberg-Neifach and Lue, 2015; Sepšiová et al., 2016; Červenák et al., 2017). 
TABLE 1 | Variability of telomeric repeats.

\begin{tabular}{|c|c|c|c|c|}
\hline Species & Taxonomical classification ${ }^{*}$ & Telomeric repeat $\left(5^{\prime} \rightarrow 3^{\prime}\right)$ & \# nt & $\%[\mathrm{G} / \mathrm{C}]$ \\
\hline Homo sapiens & $\mathrm{A} / \mathrm{M}$ & TTAGGG & 6 & $50 / 0$ \\
\hline Arabidopsis thaliana & $P$ & TTTAGGG & 7 & $43 / 0$ \\
\hline U. maydis & F/B & TTAGGG & 6 & $50 / 0$ \\
\hline N. crassa & F/A/P & TTAGGG & 6 & $50 / 0$ \\
\hline Y. lipolytica & F/A/S & TTAGTCAGGG & 10 & $40 / 10$ \\
\hline C. parapsilosis & F/A/S & TtgAttaTacTGagGTCCGGATG & 23 & $30 / 13$ \\
\hline S. cerevisiae & F/A/S & $\mathrm{TG}_{2-3}(\mathrm{TG}) 1-6$ & $5-16$ & $(\max ) 56 / 0$ \\
\hline S. pombe & F/A T & $\mathrm{G}_{2-8}$ TTACAC $_{0-1}$ & $7-14$ & $(\max ) 57 / 14$ \\
\hline
\end{tabular}

Representative examples that defy the rule that the telomeric repeat is conserved, short and G-rich are shown (reviewed in Červenák et al., 2017). Small letters in the corresponding sequences indicate variable positions in telomeric repeats of the closely related Candida species such as C. albicans and C. parapsilosis illustrating a rapid evolution of the repeats in yeasts. *A/M, Animalia/Mammalia; P, Plantae, F/B, Fungi/Basidiomycota; F/A/P, Fungi/Ascomycota/Pezizomycotina; F/A/S, Fungi/Ascomycota/Saccharomycotina; F/A/T, Fungi/Ascomycota/Taphrinomycotina.

Over the past few years this question has been addressed through biochemical and genetic analysis of TBPs from various yeast species (Kramara et al., 2010; Lue, 2010; Visacka et al., 2012; Steinberg-Neifach and Lue, 2015; Sepšiová et al., 2016; Červenák et al., 2017). Our studies have shown that Tayl, the dsTBP of the yeast Yarrowia lipolytica (Kramara et al., 2010) exhibits lower affinity for its own telomeres than for the mammalian-type telomeric repeats (Table 1). This led us to the conclusion that "the binding properties of a DNA-binding protein are tuned to inferior values, thus enabling its dynamic association with the target DNA loci" (Visacka et al., 2012). This is in line with the conclusions that enzymes usually exhibit kinetic parameters much below the diffusion limit, and thus, that evolution does not prefer kinetically superior catalysts (Bar-Even et al., 2011).

Moreover, in line with Kováč, we have argued that the high specificity of the ancestral dsTBP at some point of evolution became a burden for performing its telomeric functions, posing a selection pressure for its replacement by a less specific DNA-binding protein (Sepšiová et al., 2016; Červenák et al., 2017). For example, in S. pombe, the Tayl homolog (Teb1) was replaced by a more flexible and less specific Tazl protein that is able to bind a wide range of telomeric repeat variants (Vassetzky et al., 1999; Sepšiová et al., 2016). Similar situations occurred in S. cerevisiae and closely related species, where the function of the principal dsTBP is fulfilled by Rap1, a protein exhibiting flexible DNA-binding properties (Piña et al., 2003; Steinberg-Neifach and Lue, 2015). In contrast, when the telomeres of S. cerevisiae are artificially "humanized," Rap1 is no longer able to fulfill its telomeric function, and a more specific protein (e.g., Tbf1) is recruited to the chromosomal ends (Brevet et al., 2003). These results imply that fine-tuning of DNA-binding specificity (in either direction) accompanied co-evolution of TBPs with telomeric repeats in ascomycetous yeasts.

Recently, Glustrom et al. performed an elegant systematic analysis of the effects of amino acid substitutions across the ssTBP of S. cerevisiae (Cdc13p) DNA-binding interface on its affinity and specificity toward heterogeneous telomeric repeats of the host cell (Glustrom et al., 2018). The authors showed that, as they expected, a subset of mutants exhibiting a significant loss in affinity in vitro also conferred a profound loss of viability in vivo. To the authors' surprise the mutant proteins with an increased specificity conferred "a gradient of viability in vivo that paralleled the loss in sequence tolerance in vitro, arguing that binding specificity can be fine-tuned to ensure optimal function." They conclude "while it is common to observe loss of function upon loss of a biochemical activity, the enhancement of specificity leading to a substantial reduction in biological function has not been reported previously in nucleic acid recognition, to the best of our knowledge."

We appreciate the elegance of the study and agree that "binding specificity is fine-tuned to ensure optimal function." However, we do not share the authors' conclusion that reduction in biological function has not been reported previously in nucleic acid recognition. The examples mentioned above demonstrate that during the evolution of telomeres in the ascomycetous fungi, bi-directional changes in specificity of DNA-binding proteins have been encountered numerous times. An extreme example is a mitochondrial telomere-binding protein (mtTBP) of Candida parapsilosis. Its low binding specificity enables it to provide two crucial functions in vivo-to protect the single-stranded telomeric overhang of linear mitochondrial DNA and to function as a non-specific single-stranded DNA-binding (SSB) protein involved in the replication of the mitochondrial DNA (Tomáška et al., 1997, 2001; Nosek et al., 1999).

Indeed, the idea that in the matter of DNA-binding the stronger and more specific may not be "functionally" the better is not limited to telomeres but has also been observed in the case of other DNA-binding proteins. For example, particular mutations that increase the binding affinity of herpes simplex virus processivity factor UL42 to DNA result in reduced DNA replication fidelity (Jiang et al., 2009). Furthermore, studies investigating the evolution of transcription factors indicate that 
decreasing specificity accompanied by an increase in flexibility of DNA-binding depends on an evolutionary context (e.g., Ramos and Barolo, 2013; McKeown et al., 2014).

In summary, the results of Glustrom et al. (2018) nicely complement the conclusions inferred from previously published studies on the puzzling diversity of yeast telomeres as well as on the evolution of DNA-binding proteins. In more general terms, they also provide additional evidence that increasing perfection of molecular recognition does not necessarily mean an optimal evolutionary strategy (Kováč, 1987; Bar-Even et al., 2011).

\section{REFERENCES}

Bar-Even, A., Noor, E., Savir, Y., Liebermeister, W., Davidi, D., Tawfik, D. S., et al. (2011). The moderately efficient enzyme: evolutionary and physicochemical trends shaping enzyme parameters. Biochemistry 50, 4402-4410. doi: 10.1021/bi2002289

Blackburn, E. H. (2010). Telomeres and telomerase: the means to the end (Nobel lecture). Angew. Chem. Int. Ed. Engl. 49, 7405-7421. doi: $10.1002 /$ anie.201002387

Brevet, V., Berthiau, A. S., Civitelli, L., Donini, P., Schramke, V., Géli, V., et al. (2003). The number of vertebrate repeats can be regulated at yeast telomeres by Rap1-independent mechanisms. EMBO J. 22, 1697-1706. doi: 10.1093/emboj/cdg155

Červenák, F., Juríková, K., Sepšiová, R., Neboháčová, M., Nosek, J., and Tomáška, L. (2017). Double-stranded telomeric DNA binding proteins: diversity matters. Cell Cycle 16,1568-1577. doi: 10.1080/15384101.2017.1356511

de Lange, T. (2018). Shelterin-mediated telomere protection. Annu. Rev. Genet. 52, 223-247. doi: 10.1146/annurev-genet-032918-021921

Glustrom, L.W., Lyon, K.R., Paschini, M., Reyes, C.M., Parsonnet, N.V., Toro, T.B., et al. (2018). Single-stranded telomere-binding protein employs a dual rheostat for binding affinity and specificity that drives function. Proc. Natl. Acad. Sci. U.S.A. 115, 10315-10320. doi: 10.1073/pnas.1722147115

Gunisova, S., Elboher, E., Nosek, J., Gorkovoy, V., Brown, Y., Lucier, J.F., et al. (2009). Identification and comparative analysis of telomerase RNAs from Candida species reveal conservation of functional elements. RNA 15, 546-559. doi: 10.1261/rna.1194009

Guzmán, P.A., and Sánchez, J.G. (1994). Characterization of telomeric regions from Ustilago maydis. Microbiology 140, 551-557. doi: 10.1099/00221287-140-3-551

Jiang, C., Komazin-Meredith, G., Tian, W., Coen, D.M., and Hwang, C.B. (2009). Mutations that increase DNA binding by the processivity factor of herpes simplex virus affect virus production and DNA replication fidelity. J. Virol. 83, 7573-7580. doi: 10.1128/JVI.00193-09

Kordyukova, M., Olovnikov, I., and Kalmykova, A. (2018). Transposon control mechanisms in telomere biology. Curr. Opin. Genet. Dev. 49, 56-62. doi: 10.1016/j.gde.2018.03.002

Kováč, L. (1987). Overview: bioenergetics between chemistry, genetics, and physics. Curr. Top. Bioenerg. 15, 331-372.

Kramara, J., Willcox, S., Gunišová, S., Kinský, S., Nosek, J., Griffith, J.D., et al. (2010). Tayl protein, a novel telomere binding factor from Yarrowia lipolytica. J. Biol. Chem. 285, 38078-38092. doi: 10.1074/jbc.M110.127605

Lue, N.F. (2010). Plasticity of telomere maintenance mechanisms in yeast. Trends Biochem. Sci. 35, 8-17. doi: 10.1016/j.tibs.2009.08.006

McKeown, A.N., Bridgham, J.T., Anderson, D.W., Murphy, M.N., Ortlund, E.A., and Thornton, J.W. (2014). Evolution of DNA specificity in a transcription factor family produced a new gene regulatory module. Cell 159, 58-68. doi: 10.1016/j.cell.2014.09.003

\section{AUTHOR CONTRIBUTIONS}

All authors listed have made a substantial, direct and intellectual contribution to the work, and approved it for publication.

\section{FUNDING}

The work specifically related to the evolution of telomere-binding proteins has been supported by grants from the Slovak Research and Development Agency APVV (0035-11 \& 15-0022) and the Slovak Grant Agency VEGA (1/0052/16).

Nosek, J., Tomáška, L., Pagáčová, B., and Fukuhara, H. (1999). Mitochondrial telomere-binding protein from Candida parapsilosis suggests an evolutionary adaptation of a nonspecific single-stranded DNA-binding protein. J. Biol. Chem. 274, 8850-8857. doi: 10.1074/jbc.274.13.8850

Piña, B., Fernández-Larrea, J., García-Reyero, N., and Idrissi, F.Z. (2003). The different (sur)faces of Raplp. Mol. Genet. Genomics 268, 791-798. doi: 10.1007/s00438-002-0801-3

Ramos, A.I., and Barolo, S. (2013). Low-affinity transcription factor binding sites shape morphogen responses and enhancer evolution. Philos. Trans. R. Soc. Lond. B Biol. Sci. 368:20130018. doi: 10.1098/rstb.2013.0018

Schechtman, M.G. (1990). Characterization of telomere DNA from Neurospora crassa. Gene 88, 159-165. doi: 10.1016/0378-1119(90)90027-O

Sepšiová, R., Nečasová, I., Willcox, S., Procházková, K., Gorilák, P., Nosek, J., et al. (2016). Evolution of telomeres in Schizosaccharomyces pombe and its possible relationship to the diversification of telomere binding proteins. PLOS ONE 11:e0154225. doi: 10.1371/journal.pone.0154225

Steinberg-Neifach, O., and Lue, N.F. (2015). Telomere DNA recognition in Saccharomycotina yeast: potential lessons for the co-evolution of ssDNA and dsDNA-binding proteins and their target sites. Front. Genet. 6:162. doi: 10.3389/fgene.2015.00162.

Tomáška, L., Makhov, A.M., Nosek, J., Kucejová, B., Griffith, J.D. (2001). Electron microscopic analysis supports a dual role for the mitochondrial telomere-binding protein of Candida parapsilosis. J. Mol. Biol. 305, 61-69. doi: 10.1006/jmbi.2000.4254

Tomáška, L., Nosek, J., and Fukuhara, H. (1997). Identification of a putative mitochondrial telomere-binding protein of the yeast Candida parapsilosis. J. Biol. Chem. 272, 3049-3056. doi: 10.1074/jbc.272.5.3049

Vassetzky, N. S., Gaden, F., Brun, C., Gasser, S. M., and Gilson, E. (1999). Tazlp and Teb1p, two telobox proteins in Schizosaccharomyces pombe, recognize different telomere-related DNA sequences. Nucleic Acids Res. 27, 4687-4694. doi: $10.1093 /$ nar/27.24.4687

Visacka, K., Hofr, C., Willcox, S., Nečasová, I., Pavloušková, J., Sepšiová, R., et al. (2012). Synergism of the two Myb domains of Tayl protein results in high affinity binding to telomeres. J. Biol. Chem. 287, 32206-32215. doi: $10.1074 /$ jbc.M114.552828

Conflict of Interest Statement: The authors declare that the research was conducted in the absence of any commercial or financial relationships that could be construed as a potential conflict of interest.

Copyright (c) 2019 Tomáška, Nosek, Sepšiová, Červenák, Juríková, Procházková, Neboháčová, Willcox and Griffith. This is an open-access article distributed under the terms of the Creative Commons Attribution License (CC BY). The use, distribution or reproduction in other forums is permitted, provided the original author(s) and the copyright owner(s) are credited and that the original publication in this journal is cited, in accordance with accepted academic practice. No use, distribution or reproduction is permitted which does not comply with these terms. 